\title{
Propositionalism about intention: shifting the burden of proof
}

\author{
Lucy Campbell \\ Faculty of Philosophy, University of Oxford, Oxford, UK \\ lucy.campbell@philosophy.ox.ac.uk
}

ORCID ID: 0000-0001-8778-524X

Academia.edu: https://warwick.academia.edu/LucyCampbell

\begin{abstract}
According to a widespread view in the philosophy of mind and action, intentions are propositional attitudes. Call this view 'Propositionalism about Intention'. The key alternative holds that intentions have acts, or do-ables, as their contents. Propositionalism is typically accepted by default, rather than argued for in any detail. By appealing to a key metaphysical constraint on any account of intention, I argue that on the contrary, it is the Do-ables View which deserves the status of the default position, and Propositionalism which bears the burden of proof. I go on to show that this burden has not been met in the literature.
\end{abstract}

Keywords: intention, propositional attitudes, non-propositional attitudes, executing an intention, philosophy of action, intentional action 


\section{Introduction: propositions and do-ables, language and metaphysics ${ }^{1}$}

It is standard in much contemporary philosophy of mind and action to treat intentions as propositional attitudes. The following expressions of the idea are pretty typical: ${ }^{2}$

If we let ' $A$ ' stand for such attitude verbs as 'believe', 'desire', 'hope', 'intend', 'think', etc., then the propositional attitude statements all have the form: $S$ As that $P$. (Aydede 2010)

We may call those verbs mental that express propositional attitudes like believing, intending, desiring, hoping, knowing, perceiving, noticing, remembering, and so on. (Davidson 2001, 210)

I shall assume that intentions and beliefs are propositional attitudes. That is to say, they are states of mind that have contents, and their contents are propositions. (Broome 2002, 87, see also 2001b, 2001a)

... we should take as our definiendum [when giving an account of intention] $S$ intends that $p$, where $p$ stands for any sentence (in the appropriate grammatical form). (Davis 1984)

What exactly is the propositional content of a given intention, according to this standard view? Its proponents don’t always say. Shah and Silverstein, for example, speak consistently of "intend[ing] that p" (2013, 102 et passim), but when giving concrete examples speak of, for instance, "intend[ing] to drive to LA tomorrow" (104; my italics). Coliva (2016, 1-2) lists intentions amongst the propositional attitudes, but goes on to talk about intending to $\varphi$. In both cases we are told that intentions to $\varphi$ have propositional contents, but we are not told which propositional content they have, or how to identify them. 
It is not simply obvious which propositional content a given intention is supposed to have, as it is for example in the case of belief. Beliefs' propositional contents are typically clearly identifiable from their natural language ascriptions, whose content-clauses are very often sentences in the indicative - the latter being the canonical tool for expressing propositions. Thus the content of my belief that I need to buy printer cartridges is the proposition that I need to buy printer cartridges; the content of my belief that that the weather is on the turn is the proposition that the weather is on the turn, and so on. By contrast, intentions' contents are typically indicted using infinitive ‘to’-constructions. I might intend to wash the dishes, or I might intend Mynn to wash them. I might intend to speak in an authoritative tone of voice, or - by doing this - for the audience to take me seriously. ${ }^{3}$ If these intentions have propositional contents, we are owed an account of how to identify them.

The standard account (Williamson 2017, 166-67; Broome 2002, 87; Davis 1984; Searle 1983, 80) of how to identify the propositional content of a given intention is roughly as follows. Distinguish intention-attributions of the form $S$ intends to $\varphi$, and those of the form $S$ intends a to $\varphi$. The propositional content of the latter is identified by predicating $\varphi$ of a. So my intention for Mynn to wash the dishes has the propositional content that Mynn will wash the dishes; my intention for the audience to take me seriously has the content that the audience will take me seriously - and so on. Ascriptions of intentions to $\varphi$ also provide us with a clear candidate for a predicate (given by ' $\varphi$ '), but they do not give us an explicit subject of which to predicate it. In these cases, the propositional content is identified by predicating $\varphi$-ing of the intender herself. So my intention to wash the dishes has the propositional content that I will wash the dishes, and my intention to speak with authority the content that I will speak with authority. ${ }^{4}$

So according to the standard account, S's intention for a to $\varphi$ is an intention that a will $\varphi$, and her intention to $\varphi$ is an intention that she $(S)$ will $\varphi$, so both have propositions of the 
form that $x$ will $\varphi$ as their contents. The difference is just in whether the identity of the $\mathrm{x}$ is explicit, or implicit, in the intention's natural language ascription (Williamson 2017, 167). ${ }^{5}$ In what follows I will refer to the view just described as ‘Propositionalism about Intention' ‘Propositionalism’ for short.

As noted, Propositionalism is the standard conception of intention-contents. It is standard in two ways: first, because it is standard to think that intentions have propositional contents, and second, because it includes the standard way of identifying which propositional content a given intention has. ${ }^{6}$ I don’t think that Propositionalism deserves this status. On the contrary, I will suggest below that our starting-point should be a non-propositional conception of intention-contents.

This non-propositional conception is what I will call the 'Do-ables View' of intentioncontents (Clark 2001; Hornsby 2016; Madden 2011; Rumfitt 1994 §4; Mueller 1977; Baier 1970). ${ }^{7}$ On this view, intentions (can) take as their contents not propositions - things which can be true - but do-ables - things which can be done. Washing the dishes is a do-able, something which can be done. When I intend to wash the dishes, it is this do-able which I intend and which is the content of my intention.

It is useful here to draw a rough and intuitive distinction, between what I will call 'own-action' and 'non-own-action' intentions. The former concern actions which, intuitively, the intender herself is to perform (my intention to wash the dishes and my intention to speak in an authoritative tone of voice are examples), whereas the latter concern other things (my intention for Mynn to wash the dishes and my intention for the audience to take me seriously are examples).

All versions of the Do-ables View agree that own-action intentions ordinarily have do-ables as their contents; they differ in their understanding of non-own-action intentions. One might hold that all intentions have do-ables as their contents, so that my intention for 
Mynn to wash the dishes is actually an intention to get Mynn to wash the dishes (Madden 2011, 342-43). Alternatively, one might think that only own-action intentions have do-ables as their contents. Taking this latter view might involve thinking of non-own-action intentions as propositional, so that I intend that Mynn will wash the dishes. Since it will simplify discussion to agree some common-ground with the Propositionalist, I will treat this version of the Do-ables View as Propositionalism's main rival. However one might instead think that non-own-action intentions have neither do-ables nor propositions as their contents - perhaps what I intend is not propositional but gerundive, i.e. Mynn's washing the dishes (Hornsby 2016). ${ }^{8}$

The way we talk about own-action intentions lends initial support to the Do-ables View. We have already seen that we do not tend to attribute intentions, and especially ownaction intentions, using the hallmark of propositional contents, an indicative that-clause. We can add that forcibly rendering own-action intention-ascriptions in obviously propositional form sounds unnatural, jarring, potentially even ungrammatical. One might wonder how 'I intend that I will wash the dishes' could be the most perspicuous way of indicating my intention's content - as the Propositionalist must hold - whilst at the same time sounding at best procrustean, and at worst, ill-formed.

But the Propositionalist will point out that facts about what it is more or less natural to say does not force on one any particular explanation of these facts. It sounds very strange indeed, from a natural-language perspective, to parse 'The present King of France is bald' as 'There is a unique $\mathrm{x}$ such that $\mathrm{x}$ currently reigns over France and $\mathrm{x}$ is bald', but this is not on its own a good reason to think that Russell's Theory of Descriptions is false. It is consistent with a sentence's sounding natural that it does not accurately reveal the sentence's logical form, and consistent with a sentence’s sounding unnatural that it does. Propositionalists thus tend to dismiss the way in which we talk about intentions in natural language, and intuitions 
about natural-soundingness as mere pragmatic phenomena, and so as raising no difficulty for their view (Williamson 2017, 167).

I think that our natural language practices do lend some initial plausibility to the Doables View over Propositionalism. But I agree that attention to linguistic phenomena such as those above is insufficient on its own to decide between the two approaches. In order to do so, I think that we need to attend to deeper - specifically, to metaphysical - considerations. In what follows I shall do just this.

In a bit more detail: the next section introduces what I call Baier’s Constraint, a metaphysical constraint demanding that an account of intention explains why executing some own-action intentions involves acting on oneself, whereas executing others does not. The Doables View can meet Baier’s Constraint very easily; Propositionalism can’t. The best strategy for the Propositionalist, I argue in section 3, is to distinguish between two kinds of selfreference which might feature in the content of an intention that one will $\varphi$; the ordinary de se, and a special, purely agential, “I”. But considerations of theoretical parsimony demand that this special new "I" is introduced only if there are convincing independent arguments which favour Propositionalism over the rival Do-ables View. I argue in section 4 that there are not. It will emerge that contra the current orthodoxy, Propositionalism is not a legitimate default position but bears the burden of proof, a burden which has not been met.

\section{Baier's Constraint}

\subsection{Baier's Constraint}

Executing our intentions involves exerting our causal powers in some way. But how exactly do we direct our causal powers when we execute an intention? Consider my non-own-action intention for Mynn to wash the dishes. For this intention to be executed, I'm going to have to get Mynn to wash the dishes - my intention won't count as executed if she washes them, but 
purely off her own bat. In executing this intention my causal powers are directed at Mynn, in a way which results in her washing the dishes.

How are our causal powers directed when we execute our own-action intentions? Well, there are cases and cases. Ordinarily, I can execute my intention to wash the dishes simply by acting on the dishes, without also needing to act on myself. But there are cases in which I will act on myself. I may need to do this if I am particularly exhausted, for instance, or overcome with apathy. In such a case, I may need to use much the same kind of strategy for getting myself to wash the dishes as I might use for getting Mynn to do so: I might promise Mynn a slice of cake as a treat for completing the task, or I might promise myself a slice of cake. I might remind Mynn how much nicer it is to wake up to a tidy kitchen than a pile of washing-up, or I might remind myself of this. I might shout “GET ON WITH IT!!!” at Mynn, or shout this at myself - whether out loud or under my breath. Any of these acts might be aimed at Mynn; causing her to wash the dishes - or at myself; causing myself to wash them.

Any account of intending needs to accommodate and explain the following general distinction concerning the metaphysics of intention execution:

Baier's Distinction:

Some of our own-action intentions are executed by $\varphi$-ing, and some by getting or causing ourselves to $\varphi .^{9}$

Call the need to accommodate and explain Baier’s Distinction 'Baier’s Constraint'.

\subsection{Baier's Constraint and the Do-ables View}


The Do-ables View can meet Baier's Constraint in a very straightforward and plausible way, as a difference between a kind of own-action intention which concerns one's acting in the way in question, and a kind of own-action intention which concerns simply acting in the way in question. That is, the distinction can be understood as being between a kind of own-action intention whose content includes reference to the intender as agent, and a kind of own-action intention whose content is a do-able and thus includes reference only to the action she intends to do, and not also to herself. ${ }^{10}$

The underlying thought is that the way in which one's causal powers must be directed in order for one's intention to be executed reflects the way in which one's mind is directed in so intending. Where executing an own-action intention requires acting on myself, it is an intention for myself to $\varphi$, and can here be understood as having the proposition that I will $\varphi$ as its content. Where executing an own-action intention does not require acting on myself, it is not an intention for myself to $\varphi$, but has a subjectless content, viz. the do-able $\varphi$-ing.

\subsection{Propositionalism and Baier's Constraint}

The Propositionalist can’t meet Baier’s Constraint in the way just sketched, because on her view, all own-action intentions are intentions for oneself to $\varphi$. If it's right to think that the way in which one's causal powers are directed in executing an intention track the way one's mind is directed in having the intention, then Propositionalism entails that executing any own-action intention would involve acting on oneself. But this collapses Baier's Distinction rather than explaining it.

What options does the Propositionalist have for meeting Baier’s Constraint? I consider and reject three suggestions here, before turning to a more promising strategy in section 3. 
Basic actions. The first suggestion is that rather than explaining Baier's Distinction by reference to a difference in structure amongst own-action intentions, we should explain it by reference to a difference in the type of action intended in each case. The relevant suggested difference is that between basic actions (those one can simply do), and non-basic actions (those one can do only by doing something else). ${ }^{11}$ Call an intention to perform a basic action a basic intention, and an intention to perform a non-basic action a non-basic intention. The suggestion is that executing a non-basic intention to $\varphi$ requires acting on oneself (causing oneself to $\varphi$ ), whereas executing a basic intention to $\varphi$ requires simply acting ( $\varphi$-ing).

Not everyone thinks that the basic/non-basic action distinction is a good one (for objections to it, see Lavin 2013; Thompson 2008, 106-15). But even assuming that the distinction is a good one, it does not help the Propositionalist to meet Baier’s Constraint, because Baier’s Distinction and the basic/non-basic intention distinction come apart.

Most obviously, one can execute a non-basic intention to $\varphi$ without causing oneself to $\varphi$. Executing my intention to wash the dishes might involve or require causing myself to wash the dishes (acting on myself), but the ordinary case is that I execute it by simply washing the dishes (acting only on the dishes). Yet washing the dishes is not a basic action; I do it by doing various things - turning on the tap, picking up the sponge, and so on.

Less obviously, but perhaps also plausibly, executing a basic intention might sometimes involve acting on oneself. Assume that because of acute social anxiety, I need to get myself to say 'hello' to Professor Jonathan Bigcheese sitting to my left at the conference dinner - by giving myself a pep-talk. Does this entail that saying 'hello' is not a basic action? Seemingly not: the fact that I need to get or cause myself to say 'hello' by giving myself a pep-talk doesn’t mean that I say 'hello’ by giving myself a pep-talk. 'Giving myself a peptalk' and 'saying 'hello'” thus appear not to be two descriptions of the same action, related as more to less basic. They appear to describe separate performances, the one a cause of the 
other. This looks like a case in which a basic action, saying 'hello' to Prof. Bigcheese, is nonetheless one I cause myself to perform.

The upshot is that the basic/non-basic intention distinction can't help the Propositionalist meet Baier's Constraint because it dissociates from Baier's Distinction in at least one direction, and plausibly two.

Intentions as causally self-referential. Some Propositionalists add a level of complexity to the basic conception of intention-contents sketched above, construing intentions as causally self-referential (e.g. Velleman 1989, esp. chs. 3 \& 4; Searle 1979, 1983, ch. 3). On this view, intending to $\varphi$ is not simply intending that one will $\varphi$, but intending that one will $\varphi$ as a result of this very intention. This version of Propositionalism allows its proponent to distinguish between:

a. An intention (of mine) that I will wash the dishes as a result of this very intention b. An intention (of mine) that I will wash the dishes as a direct result of this very intention With this picture in mind it might be suggested that intentions of the form (a) are consistent with being executed by acting on oneself, whereas intentions of the form (b) are not, thus accommodating Baier’s Distinction. ${ }^{12}$

The suggestion won’t do as it stands because (b)-type intentions are a sub-class of (a)type intentions, whilst Baier's Distinction is between mutually exclusive classes of intentions. Instead, however, we can distinguish between (b) and:

a*. An intention (of mine) that I will wash the dishes as an indirect result of this very intention 
But Baier's Distinction is no better captured by the distinction between (a*)-type and (b)-type intentions than it was by the distinction between non-basic and basic intentions. In fact, the distinction between (a*)-type intentions and (b)-type intentions is the distinction between non-basic and basic intentions - at least it is the form the latter distinction takes in the context of the causally self-referential version of Propositionalism. An (a*)-type intention is one whose execution goes via the execution of another intention; a (b)-type intention is one whose intention does not do this. If the basic/non-basic intention distinction fails to map on to Baier’s Distinction, then so does the (a*)-type/(b)-type intention distinction.

The upshot is that adding a causally self-referential clause into the supposed propositional content of intentions does not help the Propositionalist to meet Baier's Constraint.

Intending that I will get myself to $\varphi$. The suggestion just floated attempted to accommodate Baier's Distinction as a distinction between two forms of self-referential propositional intention. The Propositionalist might suggest another way of doing this, understanding those intentions which can be executed without acting on oneself as intentions that one will $\varphi$, and intentions which are executed by getting oneself to act as intentions that one will get oneself to $\varphi$.

But this suggestion gives rise to more questions than it answers. Compare the following:

i. My intention that Mynn will wash the dishes

ii. My intention that I will wash the dishes

iii. My intention that I will get/cause myself to wash the dishes

Compare (i) and (ii). On the present view, (i) and (ii) are alike with respect to the structure of their contents, but different with respect to their causal execution requirements. They are both 
intentions that $x$ will $\varphi$, but whereas executing (i) involves directing my causal powers at $\mathrm{x}$ and causing it to $\varphi$, executing (ii) involves directing my causal powers away from $\mathrm{x}$. If executing my intention that Mynn will wash the dishes involves causing Mynn to wash the dishes, why should executing my intention that I will wash the dishes not involve causing myself to wash the dishes? If executing my intention that I will wash the dishes involves directing my causal powers away from myself, why should executing my intention that Mynn will wash the dishes not involve directing my causal powers away from Mynn?

Now compare (i) and (iii). On the present view these are alike with respect to their causal execution requirements: executing both requires causing $\mathrm{x}$ to $\varphi$. But they differ in the structure of their contents: one is an intention that $\mathrm{x}$ will $\varphi$, and the other is an intention that $\mathrm{x}$ will get/cause $\mathrm{x}$ to $\varphi$. Whilst an intention whose execution is constituted by getting/causing Mynn to wash the dishes is understood here as an intention that Mynn will wash the dishes, an intention whose execution is constituted by getting/causing myself to wash the dishes is understood not - by analogy - as an intention that I will wash the dishes, but as the differently-structured intention that I will get/cause myself to wash the dishes. If executing my intention that Mynn will wash the dishes requires getting/causing Mynn to wash the dishes, why shouldn't we expect my intention that I will get/cause myself to wash the dishes to require getting/causing myself to get/cause myself to wash the dishes?

We are left with a very strange view, which contains several unexplained disanalogies between non-own-action intentions and the two kinds of own-action intentions captured by Baier's Distinction. If the Propositionalist can avoid this result, then she should.

One way of doing so would be to deny that non-own-action intentions are ever structured as in (i) above, understanding my intention for Mynn to wash the dishes instead along the lines of: 
i*. My intention that I will get Mynn to wash the dishes

This view denies the possibility of an intention that $\mathrm{x}$ will $\varphi$ in which $\mathrm{x}$ is anything other than the intender herself. This would allow all intentions that $\mathrm{x}$ will $\varphi$ to be executed in the same way (simply by $\varphi$-ing), and all intentions that one will get $\mathrm{x}$ to $\varphi$ to be executed in the same way (by causing the $\mathrm{x}$ to $\varphi$ ) - thus avoiding the troubling disanalogies above ((i*) agrees with (iii), and disagrees with (ii) in relation both to its content-structure and to its causal execution-requirements).

But this is not an attractive option, because the troubling disanalogies are avoided only by, in effect, denying the existence of non-own-action intentions: apparently non-ownaction intentions for $\mathrm{x}$ to $\varphi$ turn out to have contents of the form that I will get $\mathrm{x}$ to $\varphi$. The move from (i) to $\left(i^{*}\right)$ was precisely an instance of this. And thinking of all intentions as ownaction intentions is not a happy position.

First, most Propositionalists tend to view the class of intendable propositions as relatively unrestricted, as including but not confined to propositions concerning one's own conduct. ${ }^{13}$ Second, and in a less ad hoc vein, it is simply unattractive to collapse or deny the distinction between own-action intentions and non-own-action intentions. The distinction is an intuitive one: intuitively, some intentions - such as my intention to wash the dishes primarily concern actions we ourselves are to perform, and some - such as my intention for Mynn to wash the dishes - don't. I think it is simply bizarre to suggest that my intention for Mynn to wash the dishes primarily concerns an action which $I$ am to perform. ${ }^{14}$

Of course it is true that my intention for Mynn to wash the dishes won’t be executed unless I also execute some own-action intention; an intention to bribe her to wash them, or what have you. But the fact that executing a non-own-action intention requires executing an own-action intention doesn't show that there is no non-own-action intention here, only an 
own-action one. Compare: in order for my belief that I need to buy printer cartridges to be true, my belief that I need to buy something must be true, but it would be mad to think that this shows that I only believe that I need to buy something, and not also that I need to buy printer cartridges. ${ }^{15}$

In summary, it doesn't seem attractive to try to understand Baier's Distinction as a distinction between intentions that one will $\varphi$, and intentions that one will get oneself to $\varphi$.

To sum up this section. Any account of intention needs to meet Baier's Constraint: it must accommodate and explain the distinction between cases in which an own-action intention to $\varphi$ is executed by simply $\varphi$-ing, and cases in which an own-action intention to $\varphi$ is executed by getting oneself to $\varphi$. The Do-ables View meets Baier's Constraint very easily. It holds that in cases of the first kind one intends the do-able $\varphi$-ing, whereas in cases of the second kind, one intends one's $\varphi$-ing, understood (for argument's sake) as intending that one will $\varphi$. I considered three ways in which the Propositionalist might try to meet Baier’s Constraint, but none of them were attractive. I turn now to a seemingly better approach.

\section{A purely agential "I"}

How should we diagnose the difficulty which Propositionalism has meeting Baier's Constraint?

One way of thinking about Baier's Distinction is as a distinction between cases in which, in executing my intention to wash the dishes, I am an agent and nothing but an agent, and cases in which I am agent in relation to dish-washing, but patient in relation to my own cajoling, or bribery, or threat - or whatever it is I do to get myself to wash the dishes.

The Do-ables View distinguishes these cases so easily because it can help itself to a very plausible idea, viz., that in having an intention, someone is in the capacity of (potential) 
agent, whilst any item referred to in the content of her intention is (eo ipso) in the capacity of (potential) patient. With this in mind, an intention the execution of which involves me solely as an agent (which involves washing the dishes without my being caused to wash them) must be one whose content must make no reference to me at all. Any reference to me in the content of an intention will guarantee that in having that intention I am not only potential agent but also potential patient, and that in executing the intention I am in fact not only agent, but patient too. Baier's Distinction ensures that acting is not always acting on ourselves - that we sometimes act without getting ourselves to act - and the Do-ables View accommodates this by holding that some own-action intentions have (subjectless) do-ables as their contents. ${ }^{16}$

The Propositionalist can’t accommodate the possibility of pure agency by taking reference to the agent out of those own-action intentions which are executed simply by $\varphi$-ing: that own-action intentions contain reference to the intender is definitional of Propositionalism. But she might try to explain Baier's Distinction as grounded in a distinction between two varieties of self-reference in the content of an intention (e.g.) that I will wash the dishes. The suggestion is that we might need to distinguish between the ordinary de se "I", and a special "I" which represents me in a purely agentive way. I will indicate the former with "I", and the latter with " $\mathrm{I}_{\mathrm{A}}$ " ('A', for 'agent'). The idea is that an intention that $I_{A}$ will wash the dishes simply cannot be executed by getting myself to wash the dishes (via bribery or what have you), because if I am caused to wash the dishes, including by myself, then I am part-patient as well as part-agent, and so not a pure agent, and so do not satisfy " $\mathrm{I}_{\mathrm{A}}$ " ${ }^{17}$

Let’s grant that, armed with “IA", the Propositionalist can meet Baier’s Constraint. The question remains whether the " $\mathrm{I}_{\mathrm{A}}$ " idea is viable and legitimately introduced. The first thing to say is that " $\mathrm{I}_{\mathrm{A}}$ " requires significant explanation and development. How is " $\mathrm{I}_{\mathrm{A}}$ " to be distinguished from the ordinary de se? We cannot do so purely by reference to the differential causal requirements on executing intentions containing "I" and " $\mathrm{I}_{\mathrm{A}}$ " respectively, since it is 
precisely this difference that " $\mathrm{I}_{\mathrm{A}}$ " has been brought in to explain. Another question is how an intention that $I_{A}$ will wash the dishes is supposed to be substantively different from an intention with the do-able washing the dishes as its content? Ex hypothesi they have the same causal execution conditions, so how else can we understand what the real difference is supposed to be between them? I do not claim that these explanatory demands cannot be met, just that there is a burden on the Propositionalist wanting to make use of " $\mathrm{I}_{\mathrm{A}}$ " to do so before the suggestion would be worth taking seriously.

Let's suppose that these demands can be met. Even so, the Propositionalist is not out of hot water. There are questions about parsimony here. For we didn’t think we needed “ $\mathrm{I}_{\mathrm{A}}$ ” before recognising that Propositionalism might need it in order to meet Baier’s Constraint. The worry about parsimony is made more acute by recognising that it is - seemingly - not only " $\mathrm{I}_{\mathrm{A}}$ " that we would need to introduce, but an indefinite number of new, purely agential, referring terms. Plausibly, in order to avoid private language worries, any intention I can express must be one which you can ascribe to me. If I express or self-ascribe a purely agential intention to wash the dishes, then I must do so using " $\mathrm{I}_{\mathrm{A}}$ ", saying " $\mathrm{I}_{\mathrm{A}}$ will wash the dishes" (of course the subscript 'A' is not pronounced). If you are to ascribe me this very intention, then it is not sufficient to use the sentence "Campbell intends that she will wash the dishes"; you must use the sentence "Campbell intends that she $\mathrm{A}_{\mathrm{A}}$ will wash the dishes" or "Campbell intends that Campbell $\mathrm{A}_{\mathrm{A}}$ will wash the dishes"- you must use a purely agential "she $\mathrm{A}_{\mathrm{A}}$ " or “Campbell ${ }_{A}$ ” to match my purely agential “ $\mathrm{I}_{\mathrm{A}}$ ” (although again you needn’t pronounce the subscripts). There is nothing special about the fact that it's my intention at issue, and nothing special about your choosing to refer to me with "she” or "Campbell” - you could just as well have used 'the person by the bar watching the snooker'. So the problem generalises, and we seem to need to recognise purely agential versions of an indefinite number of referring terms. ${ }^{18}$ 
With these issues about parsimony in the picture, we might think that if we can get by without " $\mathrm{I}_{\mathrm{A}}$ ", then we should. One way of doing without it, of course, would be to accept the Do-ables View. The Do-ables View accrued some initial plausibility from the way in which we talk about intentions in ordinary language, and additional support from the fact that it could very easily meet Baier's Constraint. Here we can add that it does so without our needing to introducing any new theoretical tools like " $\mathrm{I}_{\mathrm{A}}$ " (although see section 4.4 for a possible objection to this claim - and for my response to it).

\section{Is Propositionalism independently motivated?}

Accepting Propositionalism requires showing how it can meet Baier’s Constraint. The best way of doing this required introducing " $\mathrm{I}_{\mathrm{A}}$ ”, and justifying introducing " $\mathrm{I}_{\mathrm{A}}$ ” required providing independent motivation for Propositionalism. So I turn now to considering whether Propositionalism is independently motivated. I will argue, of course, that it is not. At the very least we will see that there do not seem to be any convincing arguments for Propositionalism already in the literature.

I will consider six arguments for Propositionalism which are given in or suggested by the literature. Arguments 1-3 aim to motivate Propositionalism, understood as I have been understanding it throughout, as combining the idea that intentions are propositional attitudes with a specific account of how to identify these contents (see again section 1). But some considerations in the literature are apt only to secure the weaker claim that intentions are propositional attitudes, and are silent on the question of how to identify their (putative) propositional contents. Arguments 4-6 are of this kind, but consistent with my focus in the rest of my discussion, I will treat them as being used to help motivate the standard version of Propositionalism under discussion. ${ }^{19}$

\subsection{The argument from standard syntax}


Argument: The standard syntax for infinitives renders "S intends to wash the dishes" as " $\mathrm{S}$ intends [PRO to wash the dishes]”, where [PRO] is a 'covert (i.e. 'empty' or 'invisible' Pronoun Subject' (Radford 1988, 313). Propositionalists sometimes appeal to the standard syntax for infinitives as motivating their view. ${ }^{20}$ The thought is, presumably, that if the syntax of the ascription "S intents to $\varphi$ " contains reference to S - via [PRO] - in its content-clause, this assimilates it to the structure of "S intends a to $\varphi$ ". And "S intends a to $\varphi$ " is obviously a propositional intention, since it contains a subject, a, and something predicable, $\varphi$.

Response: One point at which one might put pressure on this argument is in its final move from thinking that the content-clause of the ascription "S intends to $\varphi$ " contains included [PRO], to the claim that it is propositional. One might complain that intending $S$ to $\varphi$ is not intending that $S$ will $\varphi$. I think that there is probably something in this, but recall that I have already conceded this idea to the Propositionalist (for the sake of argument) - since I am assuming a version of the Do-ables View on which non-own-action intentions, such as my intention for Mynn to wash the dishes, do have propositional contents. So I will not pursue this objection here.

A more pressing problem is that the argument assumes that the syntax of the linguistic vehicle we use to ascribe intentions is transparent to the metaphysics of things. But why assume this? Chierchia (1989), for example, has argued that accepting the [PRO] idea at the level of syntax does not commit us to holding that "[PRO to $\varphi]$ ” is propositional even at the level of semantics. More generally, recall that in section 1 I agreed with the Propositionalist that we could not use purely linguistic considerations in an argument against Propositionalism. I don't see why we should accept the Propositionalist's use of purely linguistic considerations in an argument for their view here. 
But most importantly, if we do accept that we can in principle read off the metaphysics of intending from the syntax of an intention-ascription, then the argument from standard syntax turns out to beg the question. I suspect that this goes unnoticed by Propositionalists who appeal to the standard syntax, because they don't consider the reasons why linguists think that we need the [PRO] idea. The reason why the [PRO] idea is brought in is that it is an axiom that clauses, in all cases, have NP subjects. Apparently subjectless infinitives, therefore - for example "to $\varphi$ " in "S intends to $\varphi$ " - must contain a hidden NP subject if they are to be clauses. [PRO] is introduced to make this hidden subject explicit (Radford 1988, 313).

What is assumed in the foregoing is that "to $\varphi$ " is a clause within "S intends to $\varphi$ ". What is a clause? The Concise Oxford Dictionary of Linguistics defines a clause as "A part of a sentence whose structure is itself like that of a sentence” (Matthews 2014); in his Analysing Grammar: an Introduction, Kroeger defines a clause as "the smallest grammatical unit which can express a complete proposition” (Kroeger 2005, 32). If we agree that we can read metaphysics off from syntax, then holding that "to $\varphi$ " is a clause in " $\mathrm{S}$ intends to $\varphi$ " is already holding that " $\mathrm{S}$ intends to $\varphi$ " ascribes a propositional attitude. If so then the inclusion of the [PRO] idea in the standard syntax for infinitives follows from Propositionalism, so can hardly be a premise in an argument for it.

Conclusion: The Propositionalist both needs to do more work in order to show that it is legitimate to infer metaphysical conclusions from syntactical premises, and needs to explain why "to $\varphi$ " in "S intends to $\varphi$ " should be thought of as a clause (rather than, say, an adverbial phrase).

\subsection{The argument from intention-expression}


Argument: We canonically express our intentions by making self-referential assertions (McDowell 2010; Broome 2002, 2001b; Castañeda 1972). ${ }^{21}$ I might express my intention to wash the dishes by saying "I will wash the dishes”. Assuming that rather generally, when one expresses a mental state by making an assertion, the content of the assertion is identical with the content of the mental state it expresses, then we can conclude that my intention has the propositional content that I will wash the dishes.

Response: This argument rests on a demonstrably false principle, viz. that when one expresses an intentional state by making an assertion, the content of the assertion will match the content of the intentional state expressed.

This might well be true in the special case of belief (which belief do I express when I assert "There's a blackbird in the birdbath”? Precisely a belief with the content that there's a blackbird in the birdbath). But understood as a general principle relating mental-state content to assertion-content, it would lead to the conclusion that my first-order desire for a coffee (or: to have a coffee or that I will have a coffee), when expressed as it naturally might be, by my assertion 'I want a coffee', is identical with my second-order desire for wanting a coffee (or: to want a coffee or that I want a coffee). And this is absurd.

Conclusion: It's true that I can express my intention to wash the dishes by saying "I will (am going to) wash the dishes”. But this does not show that my intention has the propositional content that I will wash the dishes.

\subsection{The self-execution argument}

Argument: Only an intender can execute her own intentions: I can't very well claim that my intention to wash the dishes has been executed if they are washed, but by Mynn rather than 
by me. This, the current argument goes, must be recorded in the content of my intention: my intention to wash the dishes must have a self-referential proposition (that I will wash the dishes) as its content rather than a subjectless do-able (washing the dishes) as proponents of the Do-ables View hold.

There are two problems with this argument.

Response 1: Plausibly, the argument proves too much. Not only my own-action intention to wash the dishes, but also my non-own-action intention for Mynn to wash the dishes is such that its execution requires me to act - to bribe Mynn to wash them, say. The argument above would collapse the distinction between own-action and non-own-action intentions, something I have already argued is to be avoided (see again section 2.3).

Response 2: But the main problem with the self-execution argument is that although it is true that the intender herself must execute her own intentions, it is neither necessary, nor possible, to explain this in terms of intentions having essentially self-referential contents.

First, we need not explain the datum that an intender herself must execute her own intentions by appealing to their having self-referential contents, because it already follows from - and so is already explained in terms of - facts concerning what is involved in executing an intention. If an intention is executed without my causal powers being manifested, then it's simply not my intention - even if what I intended comes about (see also Ferrero 2013, 77). This is a conceptual point about intending and executing intentions. Trying to explain this datum by - in addition - building self-reference into the content of every intention, would be otiose. 
Second, we cannot explain the datum that an intender must execute her own intentions in terms of facts about the content of intention. This is because, as Annette Baier points out, the content of an attitude - rather generally - is that which variable between different attitudes of that type (Baier 1970, 657-58), whereas features which are constant between members of the type belong to the nature or form of an attitude. Accepting it as a datum that an intender's intentions cannot be executed except by her, is accepting this as a fact about intentions qua intentions. So it is a fact about the form of the attitude of intending, not something to be explained in terms of intentions' contents.

Conclusion: It's true that an intender must execute her own intentions, but this does not show that her intentions have self-referential contents, so it lends no support to Propositionalism.

\subsection{Arguments from theoretical parsimony}

I have suggested that there are parsimony worries about introducing " $\mathrm{I}_{\mathrm{A}}$ ". But the Propositionalist might attempt to turn the tables, as follows:

Argument 1: We are already very strongly theoretically committed to propositions, but not to do-ables. So even if it requires introducing a new theoretical tool, “ $\mathrm{I}_{\mathrm{A}}$ ”, considerations of parsimony on balance favour Propositionalism over the Do-ables View. This kind of argument is suggested by Wayne Davies (1984) and by Mark Schroder (2012, 463).

Response to argument 1: The argument suggests that we are not theoretically committed to do-ables as we are to propositions. But who is this 'we'? The Propositionalist is, of course, not committed to do-ables, but the proponent of the do-ables view is. 
Argument 2: Perhaps the idea ought instead to be that in committing herself to do-ables, the non-Propositionalist theoretically commits herself to items to which we were not previously committed, and that this is not so for the Propositionalist, who is committed only to propositions, which we already needed for various reasons. Thus, the proponent of the Doables View can be charged with introducing new ideas, and the relative strength of our existing commitment to propositions legitimises the introduction of " $\mathrm{I}_{\mathrm{A}}$ ".

Response to argument 2: But we have already seen that we are committed to do-ables in our everyday thought and natural-linguistic practises. We appear to be no less pretheoretically committed to do-ables than we are to propositions. As well as saying of ourselves and others that we believe (hope, fear, etc.) that such-and-such is the case, we say of ourselves and others that we intend (and want, and ought, and try, and etc.) to do things, and these things which we intend are things which can be done, and which, when we execute our intentions (do what we want, etc.), we do. Everyday and familiar things like washing the dishes. So in speaking of do-ables, the proponent of the Do-ables View does not introduce any new theoretical tool, she simply focuses in on and names a feature of our existing common-sense psychological and action-theoretic understanding.

By contrast, "IA" is a tool to which the Propositionalist was committed neither theoretically nor pretheoretically, independently of trying to show how Propositionalism could meet Baier’s Constraint.

Conclusion: Considerations of parsimony don't favour Propositionalism over the Do-ables View. On the contrary, and as I argued above, they favour the Do-ables View.

\subsection{The 'do-ables vs. things done' argument}


Consider the following passage from Bruce Vermazen:

[I]t seems preferable to [think of intentions as propositional attitudes] if one reflects on how different actions as objects of intention would have to be from actions done. Actions done, for one thing, seem to be dated particulars, while "actions" as objects of intention need not be dated and seem not to be particulars. $(1993,224)$

Argument: My best shot at reconstructing Vermazen’s argument is the following:

P1. Do-ables (“actions" as the objects of intention) would have to be the same as or similar to - what is done in executing an intention.

P2. Do-ables (“actions” as the objects of intention) are not like what is done in executing an intention.

C. Do-ables (“actions" as the objects of intention) are not the contents of intentions.

P1 sounds right: what is done in executing an intention seems to need to be - or to be importantly related to - what one intended to do. Vermazen is clear about what he thinks motivates P2: do-ables are not like what is done, because do-ables are abstract, whereas what is done is concrete (dated, particular).

Response 1: Premise 2 is false: things done aren't dated particulars any more than do-ables are. If you have walked to Grantchester and I have walked to Grantchester, we have done the same thing. The thing we have each done - walking to Grantchester - is not therefore a particular. Perhaps I walked to Grantchester on Saturday afternoon, and you walked to 
Grantchester on Sunday morning: the thing we both did - walking to Grantchester - is thus not dated (see also Madden 2011, 339, and Rumfitt 1994, 619).

Of course your doing this thing is a dated particular, as is my doing it. The episode of your walking to Grantchester is distinct from the episode of my walking there: they are different episodes and happen at different times. But this shows only that things done, no less than doables, are distinct from the doing of something. This is to be expected, by analogy with propositions: what makes a proposition true is not identical with the proposition it makes true - this is a condition on propositions' being abstracta, and things are analogous in the case of do-ables.

Response 2: Vermazen asks us to reflect on how different do-ables (“actions” as objects of intention) would have to be from actions done. I have suggested that they are not different. But even if there was a difference here, it would be eclipsed by the difference between propositions and things done (as it would by the difference between propositions and the doing of things).

Conclusion: Vermazen's second premise is false, so his argument doesn't go through. Assuming his first premise is true - which seemed plausible - then it supports not Propositionalism, but to the Do-ables View.

\subsection{The argument from practical reasoning}

Objection: Practical reasoning could only operate on propositional attitudes; intentions are involved in practical reasoning, so intentions are propositional attitudes. This claim is made by John Broome (in various places, but see e.g. 2001b), and by Fodor (1978). 
Response: Obviously practical reasoning involves operations which are sensitive to the contents of the psychological attitudes it involves. But why think that these contents need to be propositional? Of course if one starts from the assumption that practical reasoning, like theoretical reasoning, is a matter of making transitions between (e.g.) truth-evaluable contents, then thinking of intentions as non-propositional attitudes will make them incapable of entering into practical reasoning: only propositional attitudes have truth-evaluable contents.

But the assumption that practical reasoning has the same form as theoretical reasoning can be rejected. Indeed there is a tradition of viewing practical and theoretical reasoning as formally distinct which stretches back to Aristotle. ${ }^{22}$ More recently, Elizabeth Anscombe (1957, 1989), Michael Thompson (2008), Jonathan Dancy (2009), and Jennifer Hornsby (2016), have all argued that, far from its being the case that we must think of intentions as propositional attitudes if we are to understand practical reasoning, we will instead only make sense of practical reasoning once we have recognised that intentions (can) have what I have been calling do-ables as their contents.

Conclusion: What is required to get an account of practical reasoning off the ground is an ability to explain the logical and normative relationships between an agent's attitudes and her actions. And there is no pre-theoretical reason to think that logical and normative relationships can hold only between attitudes whose contents take propositional form.

\section{Conclusion}

Propositionalism about Intention is currently the orthodox conception of the content of intention. It is widely held to deserve this status by default, rather than on the basis of 
sustained or careful argument. By showing the difficulties that Propositionalism has meeting

Baier's Constraint, compared to the ease with which the Do-ables View does so, I hope to have shown that Propositionalism does not deserve the status as the default conception of the content of intention. The burden of proof lies not with the proponent of the Do-ables View, but with the Propositionalist, and she has not yet shown us how it might be shouldered.

\section{References}

Alvarez, Maria. 2010. Kinds of Reasons: An Essay in the Philosophy of Action. Oxford University Press.

Anscombe, G. E. M. 1957. Intention. Harvard: Harvard University Press. . 1989. "Von Wright on Practical Inference.” In The Philosophy of Georg Henrik von Wright, edited by P. A. Schilpp. The Library of Living Philosophers. La Salle Ill.: Open Court.

Aydede, Murat. 2010. “The Language of Thought Hypothesis.” Stanford Encyclopedia of Philosophy. https://plato.stanford.edu/entries/language-thought/.

Baier, Annette C. 1970. “Act and Intent.” Journal of Philosophy 67 (19): 648-658.

Broome, John. 2001a. “Are Intentions Reasons? And How Should We Cope with Incommensurate Values?” In Practical Rationality and Preference: Essays for David Gauthier, edited by Christopher Morris and Arthur Ripstein, 98-120. Cambridge: Cambridge University Press. . 2001b. “Normative Practical Reasoning.” Aristotelian Society Supplementary Volume 75 (1): 175-93. . 2002. "Practical Reasoning." In Reason and Nature: Essays in the Theory of Rationality, edited by Jose Luis Bermudez and Alan Millar, 85-111. Oxford: Oxford University Press.

Castañeda, Hector-Neri. 1972. “Intentions and Intending.” American Philosophical Quarterly 9 (2): 139-49.

Chierchia, Gennaro. 1989. “Anaphora and Attitudes de Se.” In Semantics and Contextual Expression, edited by Renate Bartsch, J. F. A. K. van Bentham, and P. van Emde Boas, 1-31. Foris Publications.

Clark, Philip. 2001. “The Action as Conclusion.” Canadian Journal of Philosophy 31 (4): 481-505.

Coliva, Annalisa. 2016. The Varieties of Self-Knowledge. Palgrave Innovations in Philosophy. London: Palgrave Macmillan.

Dancy, Jonathan. 2009. “Action, Content, and Inference.” In Wittgenstein and Analytic Philosophy: Essays for PMS Hacker, edited by PMS Hacker and John Hyman, 27898. Oxford: Oxford University Press.

Davidson, Donald. 2001. "Mental Events.” In Essays on Actions and Events. Oxford: Clarendon Press. 
Davis, Wayne. 1984a. “A Causal Theory of Intending.” American Philosophical Quarterly 21 (1): 43-54.

Ferrero, Luca. 2013. “Can I Only Intend My Own Actions?” In Oxford Studies in Agency and Responsibility, 70-94. Oxford: Oxford University Press.

Fodor, Jerry. 1978. "Propositional Attitudes.” The Monist 61 (4): 501-23.

Grice, Paul. 1971. "Intention and Uncertainty." Proceedings of the British Academy 57: 26379.

Hornsby, Jennifer. 2016. “Intending, Knowing How, Infinitives.” Canadian Journal of Philosophy 46 (1): 1-17.

. 2017. "Knowledge How in the Philosophy of Action." Royal Institute of Philosophy Supplement 80: 87-104.

Kroeger, Paul R. 2005. Analysing Grammar: An Introduction. Cambridge: Cambridge University Press.

Lavin, Douglas. 2013. “Must There Be Basic Action?” Noûs 47 (2): 273-301.

Lewis, David. 1973. Counterfactuals. Oxford: Oxford University Press.

Madden, Rory. 2011. "Intention and the Self." Proceedings of the Aristotelian Society CXI (3): 325-51.

Matthews, P. H. 2014. The Concise Oxford Dictionary of Linguistics. 3rd ed. Oxford: Oxford University Press.

McDowell, John. 2010. "What Is the Content of an Intention in Action?” Ratio 23 (4): 415432.

Mueller, Anselm. 1977. “Radical Subjectivity: Morality Versus Utilitarianism.” Ratio 19 (2): 115-32.

Price, A. W. 2016. “Choice and Action in Aristotle.” Phroenesis 61: 435-62.

Radford, Colin. 1988. Transformational Grammar: A First Course. Cambridge Textbooks in Linguistics. Cambridge: Cambridge University Press.

Rumfitt, Ian. 1994. "Frege's Theory of Predication: An Elaboration and Defense, with Some New Applications.” The Philosophical Review 103 (4): 599-637.

Schroeder, Mark. 2012. “The Ubiquity of State-Given Reasons.” Ethics 122 (3): 457-88.

Searle, John R. 1979. “The Intentionality of Intention and Action.” Inquiry 22 (1-4): 253280.

1983. Intentionality. Cambridge: Cambridge University Press.

Shah, Nishi, and Matthew Silverstein. 2013. "Reasoning in Stages.” Ethics 124 (1): 101-13.

Stanley, Jason. 2011. Know How. Oxford: Oxford University Press.

Thompson, Michael. 2008a. Life and Action: Elementary Structures of Practice and Practical Thought. Harvard University Press.

. 2008b. “Naive Action Theory.” In Life and Action. Harvard University Press.

Velleman, David. 1989. Practical Reflection. Princeton University Press.

Vermazen, Bruce. 1993. “Objects of Intention.” Philosophical Studies 71 (3): 223-65.

Williamson, Timothy. 2017. “Acting on Knowledge.” In Knowledge-First: Approaches in

Epistemology and Mind, edited by J. Adam Carter, Emma C. Gordon, and Benjamin Jarvis, 163-81. Oxford: Oxford University Press.

\footnotetext{
${ }^{1}$ The ideas in this paper have benefitted from discussion with a number of people. In addition to those mentioned in footnotes below, thanks go especially to Alex Grzankowski, and in addition to Tim Crane, Alexander Greenberg, Jane Heal, Jen Hornsby, Dave Jenkins, John Maier, Daniel Morgan, Silvan Wittwer, and to the audiences at The London Mind Group and Questioning Propositionalism in Philosophy and Linguistics, a workshop at Birkbeck, University of London, Spring 2018.
} 
${ }^{2}$ See also Shah and Silverstein 2013; Coliva 2016, 1; Fodor 1978, 506; Williamson 2017; McDowell 2010; Vermazen 1993; Velleman 1989; Searle 1983, ch. 3.

${ }^{3}$ Sometimes we do use 'that' clauses, but these tend to be in the subjunctive rather than the indicative - I might intend that the audience take me seriously. That-clauses in the subjunctive do not obviously express propositional contents - for discussion (in relation to desire), see Alvarez (2010, 67-68).

${ }^{4}$ The identities of the (supposed) propositional contents of intentions are sometimes delivered in a different way, by appealing to what one would say in expressing one's intention (see e.g. McDowell 2010, 417). I can express my intention to wash the dishes with 'I will wash the dishes' or 'I'm washing the dishes', and might express my intention for Mynn to wash the dishes with 'Mynn will wash the dishes!' (Anscombe 1957, 3; Velleman 1989, 61; Grice 1971, 271). Both ways of identifying the (supposed) propositional contents of intentions have been appealed to as part of an argument for the standard view. I will consider and reject both arguments in section 4 .

${ }^{5}$ This is the basic shape of the standard account. Some add extra frills, for example holding that an intention to $\varphi$ is an intention that one will $\varphi$ as a result of this very intention. I consider this idea in 2.2.

${ }^{6}$ What I am here calling 'Propositionalism' might be rejected by someone who nonetheless accepts the idea that intentions are propositional attitudes. One person who does so is Luca Ferrero (2013; thanks to an anonymous reviewer for this journal for alerting me to this work). Ferrero objects to the idea that in general, an intention to $\varphi$ is an intention that one will $\varphi$. Rather, he thinks, the content of this intention is the intender's goal, understood as the state of affairs thereby aimed at, and brought about if the intention is successfully executed. The goal of my intention to wash the dishes, for example, would be the state of affairs of the dishes' being clean, and the propositional content of my intention would be that the dishes are (will be?) clean. My target in this paper is the orthodox version of the idea that intentions are propositional attitudes, so I won't assess Ferrero's account in the main text. Occasionally I will comment on his position in notes.

7 'Do-ables' is my label; intention-contents so-understood are also referred to in the literature cited as 'acts' or 'actions'. I prefer the label 'do-ables' because it nicely captures the inherent potentiality of what is intended.

${ }^{8}$ My sense is that this final version of the Do-ables View is, in the end, preferable (see also Alvarez 2010, 67; Hornsby 2016; Thompson 2008, 121). I reject the pure do-ables view because it collapses the distinction between own-action and non-own-action intentions, viewing all intentions as own-action intentions (for more on why this is problematic, see section 2.2 below).

${ }^{9}$ See (Baier 1970). What I here call ‘Baier’s Distinction' is not explicitly discussed by Baier, but she does discuss its very close cousins, such as the distinction between intending to $\varphi$ and intending to get oneself to $\varphi$ (e.g. 1970, 653). More generally, my reference to Baier here is aimed to highlight how much common-ground our discussions share. But we do not completely overlap for a few reasons, one of which being that whilst I am objecting to Propositionalism, Baier is objecting to Chisholm's conception of intending as (always) intending to bring it about that $p$, which is not strictly a propositionalist account - although it shares some pitfalls with the latter. For another difference between Baier's and my discussion, see note 16.

${ }^{10}$ Ferrero's account (see again note 6) can accommodate Baier's Distinction in a similar way, holding that ordinarily an intention to wash the dishes has as its content the state of affairs of the dishes' being clean, but that one's intention can also concern the state of affairs of one's cleaning the dishes. I compare Propositionalism to the Do-ables View rather than to Ferrero's propositionalist alternative because the Do-ables View is both the most commonly-held alternative - and so the main rival - to Propositionalism, and because it is prima facie better-motivated than Ferrero's propositionalist account. Whilst he argues against standard Propositionalism and in favour of his account of how to identify the propositional contents of intentions, Ferrero simply assumes without argument that intentions' contents are propositional: he argues that the content of an intention is the goal the intender has in intending, but it is an assumption in his discussion that goals are states of affairs, and so propositionally structured $(2013,73)$. So Ferrero's position is unmotivated unless he can provide an argument for the claim that intentions are propositional attitudes of some variety. (I undermine several candidate arguments for this conclusion in sections 4.4 - 4.6.) The Do-ables View, by contrast, is motivated initially by the fact that it fits nicely with our natural-language talk about intention. I have conceded that this alone is not proof of the Do-ables View, but it does give it the edge over Ferrero's view.

${ }^{11}$ This suggestion was first made to me by Hugh Mellor, and has also been pressed by various anonymous reviewers commenting on earlier versions of this paper.

${ }^{12}$ Thanks to an anonymous reviewer for this suggestion.

${ }^{13}$ For a particularly extreme version of this tendency, recall the quotation from Davis from the beginning of this paper, which characterises the definiendum of an account of intending as "S intends that $p$, where $p$ stands for any [indicative] sentence” (1984, 43; my underlining; see also Williamson 2017, 168).

${ }^{14}$ This problem also leads me to reject the idea that all intentions have do-ables as their contents (section 1).

${ }^{15}$ I also don't want to deny the important fact that we sometimes think of intentions as including one another. We can describe me as intending to bribe Mynn in order to get her to wash the dishes. But we can also (truly) 
describe me simply as intending Mynn to wash the dishes - even though my intention won't be executed unless I do something do get Mynn to wash them. Again, compare the belief case: we can describe me as believing that [I need to buy cartridges because I'm running out of ink]. But we can also describe me simply as believing that I need to buy cartridges - even where I believe this because I also believe that I'm running out of ink. For discussion see Anscombe (1957, 46-47).

${ }^{16}$ Compare Baier here: “In our language [...], the agent's special privilege is, not to insert himself into all his intentions, but to leave himself out of the basic ones.” (Baier 1970, 658) Baier here conflates the class of basic actions with the class of actions one can perform without acting on oneself - the mistake I complained about in previous section. This is part of the reason why although my discussion owes a lot to Baier's in spirit, I don't follow its letter too closely (see fn. 9).

17 John Maier, Alison Fernandes, and Daniel Morgan have all independently suggested something like this option to me.

${ }^{18}$ David Lewis, in a different context, argues that while we should care about qualitative parsimony, there is no motivation for quantitative parsimony. That is, we should be wary of introducing new types of entity if avoidable, but once we have committed ourselves to a given type of entity, it is no more problematic to think that there are a great number of them than it is to think that there are only a few (Lewis 1973, 87). Presumably the same point can be applied to theoretical tools as to entities, so it might be argued that the current argument call it the explosion argument - fails because the lack of parsimony it observes is merely the unproblematic quantitative kind. Two points in response: first, I don't want to put too much weight on the explosion argument. Perhaps its function is to emphasise the problem with the " $\mathrm{I}_{\mathrm{A}}$ " idea itself rather than to add further problems. But second, it's not clear to me whether the distinction between qualitative and quantitative parsimony can be drawn in a principled way - at least not in this case. Whether introducing e.g. "Campbell $\mathrm{A}_{\mathrm{A}}$ " in addition to " $\mathrm{I}_{\mathrm{A}}$ " is introducing a new type of theoretical tool depends on how we describe " $\mathrm{I}_{\mathrm{A}}$ ". Is it a form of reference? If so, then introducing "Campbell $\mathrm{A}_{\mathrm{A}}$ " is introducing more of the same, since "Campbell $\mathrm{A}_{\mathrm{A}}$ " is also a form of reference. Is " $\mathrm{I}_{\mathrm{A}}$ " a form of self-reference? Then introducing "Campbell ${ }_{\mathrm{A}}$ " is introducing a new type, since "Campbell $\mathrm{A}_{\mathrm{A}}$ " is not a form of self-reference.

19 Thus the failure of arguments 4-6 is a problem also for Ferrero’s propositionalist account (Ferrero 2013); see again notes 6 and 10 .

${ }^{20}$ Williamson $(2017,167)$ does so obliquely; Stanley is much more explicit in his appeal to the standard syntax, although in the context of knowing how to, rather than intending to, $\varphi$ (Stanley 2011, ch. 3). It is fair to assume that Stanley would view the argument as carrying over to intending to $\varphi$; see Hornsby $(2016,2017)$ for criticism. ${ }^{21}$ Castañeda is not a Propositionalist per se. He holds that the contents of intention are neither do-ables, nor propositions, but 'proposition-like', and self-referential (Castañeda 1972, 41). He argues against the Do-ables View (as it appears in Baier [1970]) on this basis.

22 Anthony Price (2016) argues that we ought to understand Aristotle as (implicitly) committed to the Do-ables View (only implicitly because Aristotle does not discuss things in these terms). 